\title{
The modelling and simulation of 12/8 SRM and SRD Based on Simulink
}

\author{
Bao-Xiang Dong ${ }^{1, a}$ \\ ${ }^{1}$ Electrical and Electronic Engineering Department, Zibo Vocational Institute, Zibo 255314, \\ Shandong Province, People's Republic of China \\ aniyibx@163.com
}

Keywords: SRM, SRD, Simulink

\begin{abstract}
Switched reluctance driver (SRD) is a high efficiency, new energy-saving variable speed control system. Simulink is commonly used as a simulation platform to guide the design, but there is only 6/4 switched reluctance motor (SRM) model and the widely used 12/8 SRM model is not included in Simulink component library. In this paper, a method for constructing 12/8 SRM model is given based on the study of 6/4 SRM model structure. The correctness of the model was verified by simulation and experiment. This method can be used to construct other multi-pole SRM model. A SRD simulation model, which can be used as a research platform for SRD parameters optimization and design, is built with the 12/8 SRM model.
\end{abstract}

\section{Introduction}

As a new type of variable speed control system, SRD has been widely used in industrial speed control, household appliances and other areas, for its advantages of high efficiency, high starting torque, and good speed performance. With the application fields constantly expanded, the design demands for SRD are higher and higher. It's necessary to consider control parameters, good speed control performance, the cost, short development cycle and so on. Therefore, the key problem is how to build a good simulation model of SRD for designer. Simulink is the first choice of simulation platform for engineers, many models were mentioned in the MATLAB help files [1-3], but only the simulation model mentioned in references [1] was chosen. There are three types of SRM model in Simulink: 6/4

SRM, 8/6 SRM and 10/8 SRM, but multi-pole SRM model used widely, such as 12/8 SRM, is not available. This paper presents a method for modifying 6/4 SRM model to 12/8 SRM model and the correctness has been verified by simulation and experiment. A SRD simulation model was constructed with 12/8 SRM model to guide the design and parameter optimization.

\section{The method of constructing 12/8 SRM model}

The following is the method for modifying 6/4 SRM model to 12/8 SRM model, this can be also applied to other multi-pole model building. The main difference between $12 / 8 \mathrm{SRM}$ and 6/4 SRM is the inductance cycle, the inductance cycle of 6/4 SRM is 90 degrees and the inductance cycle of $12 / 8 \mathrm{SRM}$ is 45 degrees. There are two ways to modify the SRM model, one is to modify the existing SRM model directly, and the other is to add a new model in the model library. This article takes the second approach. Open powerliv.mdl file after it's read-only attribute removed in Simulink, find the SRM model in MACHINES model library, unlock the model, copy to a new one renamed SRM128, break it's link with model library.

In SRM128 model Mask editor, delete 8/6, 10/8, leaving only 6/4, remove the selection in check box of Show Parameter, then the model can be only used for the simulation of 12/8 SRM. Add "PosSensor $=45$; ITBLD $=2$ *ITBLD; initialw $=[0,30,15] ; "$ command in the Initialization command window to change the rotor of the motor cycle to 45 degrees and double the torque value and reset the initial position angle of each phase. For SRD model in Fig 1, change 90 to 45 in Position_Sensor, and change initial angle [ $\left[\begin{array}{lll}0 & 6 & 30\end{array}\right]$ to $\left[\begin{array}{lll}0 & 30 & 15\end{array}\right]$ in the speed integral model. 


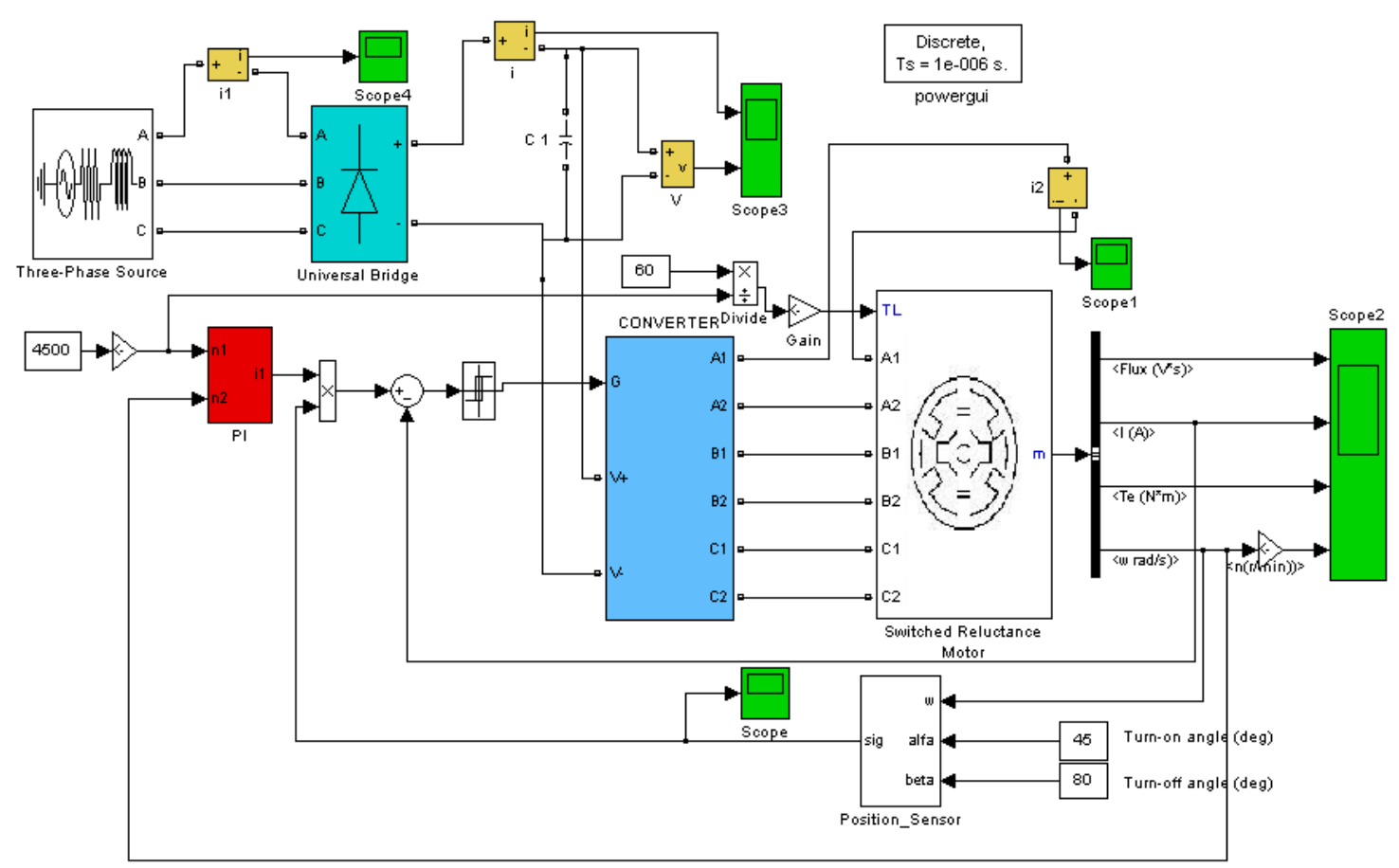

Fig. 1 The 12/8 SRD simulation model.

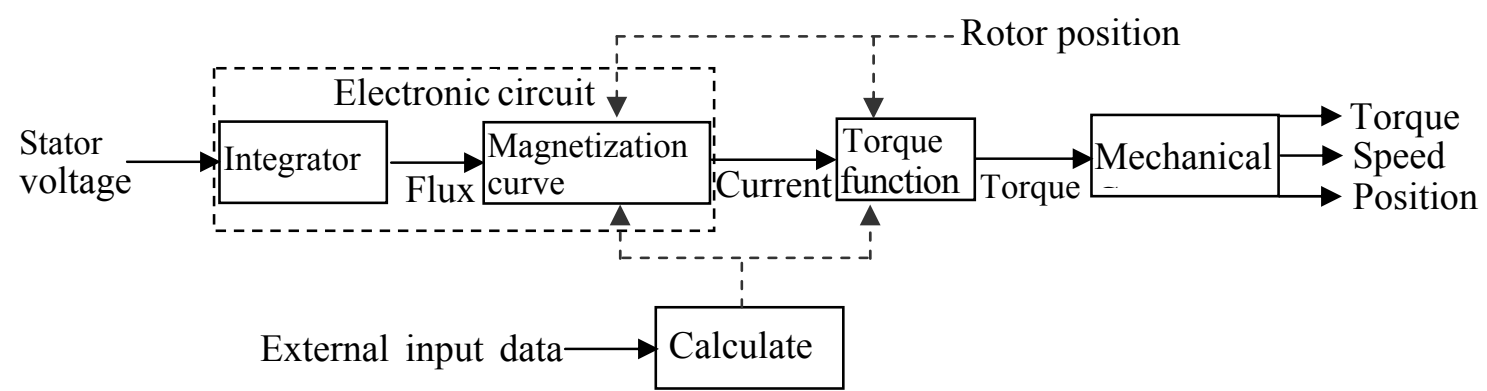

Fig. 2 The SRD structural principle.

\section{The 12/8 SRD simulation model}

The structural principle of SRD is shown in Fig 2. The input is stator voltage and the outputs are mechanical parameters (torque, speed and rotor position). The SRD consists of three parts: electronic circuit, mechanical component and torque generating component, which can be used to calculate the external inputting data of magnetization curve and the torque functions[1].

SRD is mainly composed of four parts: power converter, angular displacement sensor, SRM and controller. The 12/8 SRD simulation model shown in Fig 1 was composed of seven functional interrelated and indispensable models: rectifier, power converter, SRM, angular displacement sensor, and PI controller, etc. The rectifiers, PI controller and hysteresis comparator belong to the control circuit. SRM is powered by DC. While the motor is operating, the feedback of speed, stator and rotor position is added to the angular displacement sensor in real time. The angular displacement sensor, PI controller and hysteresis comparator together adjust the winding excitation current; finally, the SRM operation is controlled by the switching devices of the power converter.

Table 1. Parameter settings of SRM

\begin{tabular}{ccccc}
\hline $\begin{array}{c}\text { Type of } \\
\text { SRM }\end{array}$ & $\begin{array}{c}\text { Moment of inertia } \\
{[\mathrm{kg} \cdot \mathrm{m} . \mathrm{m}]}\end{array}$ & $\begin{array}{c}\text { Turn-on angle } \\
{[\mathrm{deg}]}\end{array}$ & $\begin{array}{c}\text { Turn-off angle } \\
{[\mathrm{deg}]}\end{array}$ & $\begin{array}{c}\text { Initial speed } \\
{[\mathrm{r} / \mathrm{m}]}\end{array}$ \\
\hline $\mathbf{6} / \mathbf{4}$ & 100 & 45 & 74 & 2400 \\
$\mathbf{1 2 / 8}$ & 100 & 22.5 & 37 & 1200 \\
\hline
\end{tabular}




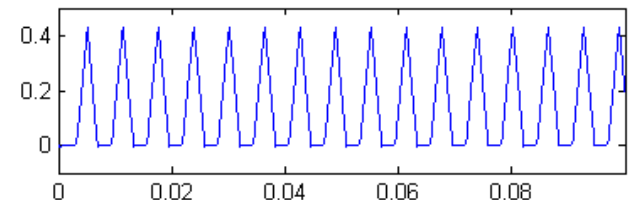

(a) Flux waveform

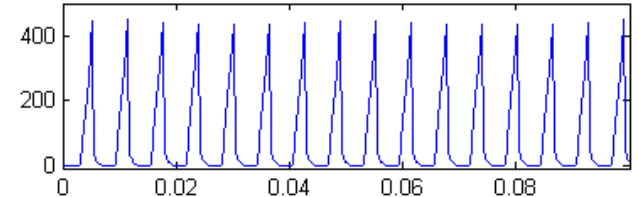

(b) Winding current waveform

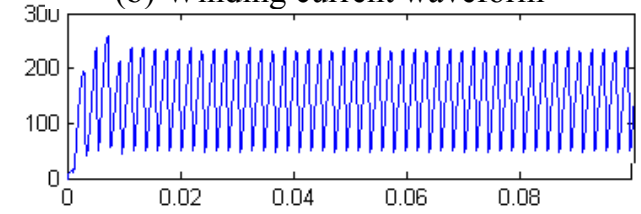

(c) Electromagnetic torque waveform

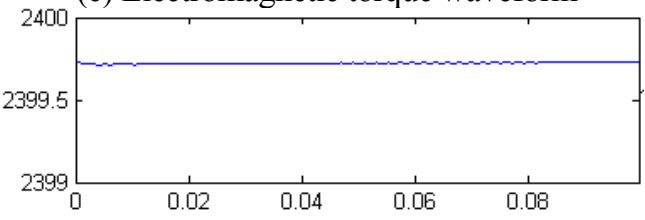

(d) Speed waveform

Fig. 3 The 6/4 SRM simulation waveforms.

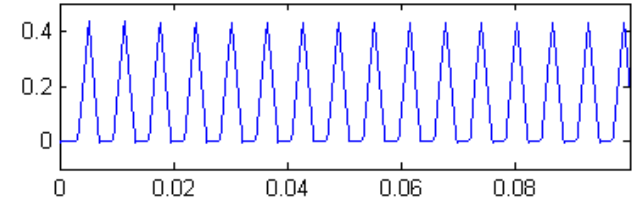

(a) Flux waveform

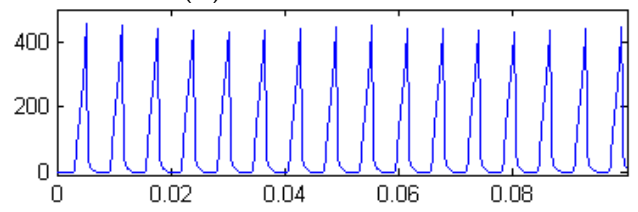

(b) Winding current waveform

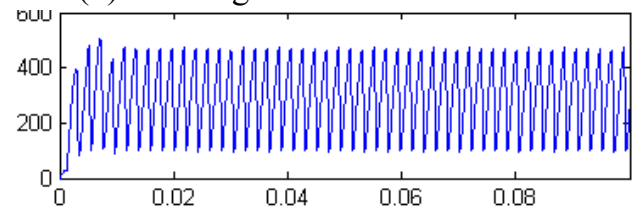

(c) Electromagnetic torque waveform

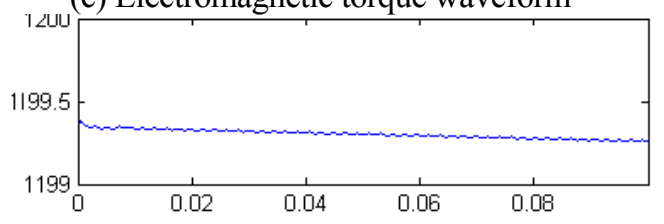

(d) Speed waveform

Fig. 4 The 12/8 SRM simulation waveforms.

\section{Verification of the 12/8 SRM model by simulation}

The inductance cycle of $6 / 4 \mathrm{SRM}$ is 90 degrees and the inductance cycle of $12 / 8 \mathrm{SRM}$ is 45 degrees, so when the speed of 12/8 SRM is half of the 6/4 SRM, the inductance cycle of them is equal. The power-on time is also equal if the opening angle and turn-off angle of 12/8 SRM is half of the 6/4 SRM. If the inductance parameters and voltage of the two SRM is equal, the flux linkage change and current is also the same. The rate of inductance change on the angle of 6/4 SRM is half of 12/8 SRM. The electromagnetic torque of 12/8 SRM is twice as much as the 6/4 SRM if the current waveform is equal. The simulation parameters are set as shown in table 1, the other parameters use the default values, and the moment of inertia was set to 100 to maintain the motor running in constant speed.

The simulation results of the two models were shown in Fig 3 and Fig 4 . It can be seen that the flux linkage and current waveforms of the two models are the same, and the torque of $12 / 8$ SRM is twice as much as the 6/4 SRM, thus the correctness of $12 / 8$ SRM was verified by simulation.

\section{Verification of the 12/8 SRM model by experiment}

The experimental platform shown in Fig 5 is composed of a three-phase 12/8 SRM rated power of $37 \mathrm{~kW}$ and speed of $1500 \mathrm{r} / \mathrm{min}$, a $132 \mathrm{~kW}$ controller, torque and speed measuring instruments, a voltage regulator, a load motor and a TDS3014B oscilloscope. The power supply is $380 \mathrm{~V}, 50 \mathrm{~Hz}$ and three-phase AC. The capacitor of DC filter is $6800 \mathrm{uF}$ because the $37 \mathrm{~kW}$ SRM was controlled by the $132 \mathrm{~kW}$ controller. The parameters of SRM and circuit in simulation model can refer to table 2 or obtained from experiment. The two current waveforms are almost the same demonstrated by the result of simulation and experiment shown in Fig $6 \sim$ Fig 8 .

To facilitate comparing, we can extract the current value from simulation and experiment data. The experiment current value can be obtained directly by measuring the voltage of sampling resistor on the DC bus. Sampling resistor value is $51 \Omega$, oscilloscope variable ratio is 5000:1, 
sampling resistor's peak-peak voltage is $1.880 \mathrm{~V}$, so the amplitude value of DC bus current is $184.3 \mathrm{~A}$. The amplitude value of DC bus current is $185 \mathrm{~A}$, the difference of current amplitude is only $0.38 \%$.

The correctness of $12 / 8 \mathrm{SRM}$ model is verified by the DC side current waveform and the amplitude comparison which obtained from simulation and experimental.

Table 2. Electromotor parameters

\begin{tabular}{|c|c|c|c|c|c|c|c|c|c|c|}
\hline $\begin{array}{l}\text { Stator } \\
\text { resistance }\end{array}$ & $\begin{array}{l}\text { Moment } \\
\text { of inertia }\end{array}$ & $\begin{array}{c}\text { Coefficient } \\
\text { of friction } \\
\text { [N.m.s }]\end{array}$ & $\begin{array}{c}\text { Turn-on } \\
\text { angle } \\
\text { [deg] }\end{array}$ & $\begin{array}{c}\text { Turn-off } \\
\text { angle } \\
\text { [deg] }\end{array}$ & Speed & $\begin{array}{l}\text { Maximum } \\
\text { inductance }\end{array}$ & $\begin{array}{c}\text { Saturated } \\
\text { inductance }\end{array}$ & $\begin{array}{c}\text { Minimum } \\
\text { inductance } \\
{[\mathrm{mH}]}\end{array}$ & $\begin{array}{c}\text { maximum } \\
\text { current } \\
{[\mathrm{A}]}\end{array}$ & $\begin{array}{c}\text { maximum } \\
\text { flux } \\
{[\text { V.s] }}\end{array}$ \\
\hline 0.1328 & 0.2889 & 0.01 & 22.5 & 36.525 & 1500 & 16 & 2 & 2 & 200 & 0.95 \\
\hline
\end{tabular}

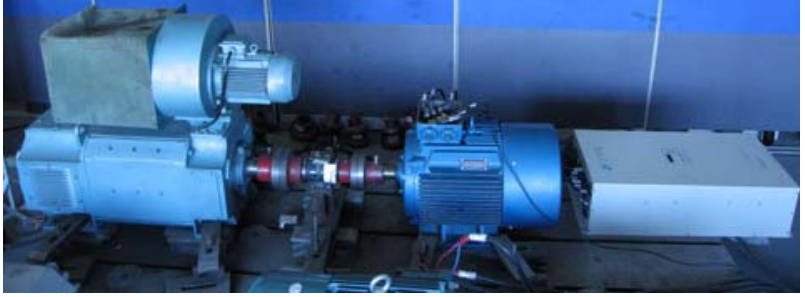

Fig. 5 Experiment platform.

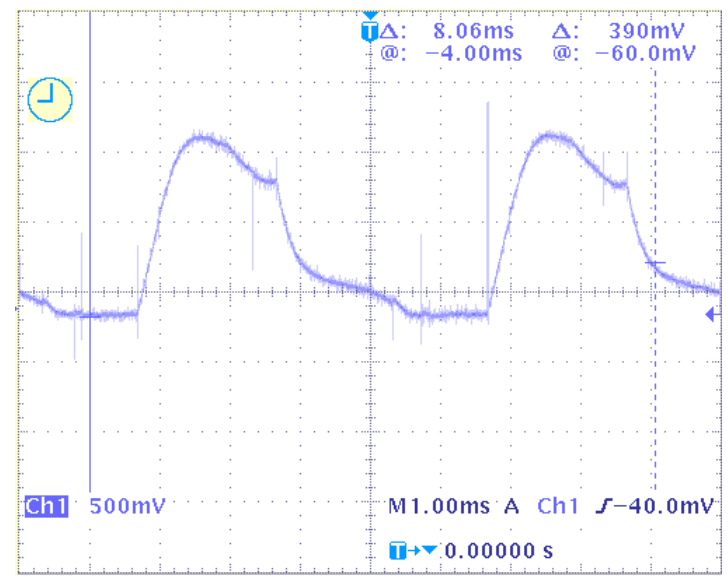

Fig. 7 Current waveforms from DC plans in experiment.

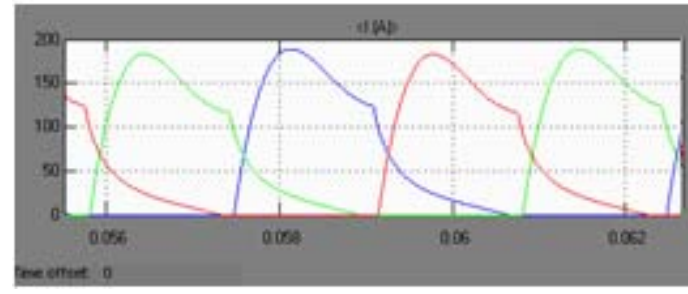

Fig. 6 Current simulation waveforms from

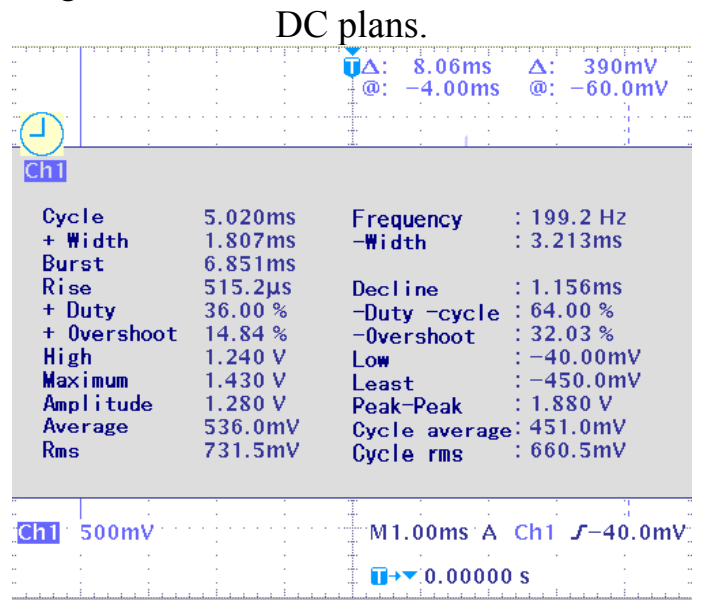

Fig. 8 Detailed data of current waveforms in experiment.

\section{Conclusions}

A method of modifying the 6/4 SRM model to 12/8 SRM model, whose correctness is verified by simulation and experiment, is proposed based on the study of 6/4 SRM model structure. The method is also effective for building other multi-pole SRM model. The SRD simulation platform built with 12/8 SRM model can be used as the SRD research platform to guide the SRD design and parameter optimization, which can facilitate the design process and reduce the cost.

\section{References}

[1] Hoang Le-Huy,Patrice Brunelle Nov. 2005 A Versatile Nonlinear Switched Reluctance Motor Model in Simulink using Realistic and Analytical Magnetization Characteristics IEEE Volume, Issue 6-10 1156-1161

[2] Jianbo Sun, Qionghua Zhan 2004 Simulation Model of Switched Reluctance Motor Based on Matlab/Simulink Ship Electronic Engineering 24 107-110

[3] D.A. Torrey, X.M. Niu, E.J. Unkauf 1995 Analytical modelling of variable reluctance machine magnetisation characteristics IEE Proceedings - Electric Power Applications 142 14-22 